\title{
An XXY sex chromosome constitution in a house musk shrew (Suncus murinus L.) with testicular hypoplasia
}

\author{
M. B. Rogatcheva ${ }^{1,2}$, S-I. Oda ${ }^{2}$, A. I. Zhelezova ${ }^{1}$ and P. M. Borodin ${ }^{1}$ \\ ${ }^{1}$ Institute of Cytology and Genetics, Novosibirsk, 630090, Russia; and ${ }^{2}$ Laboratory of Animal Management, \\ School of Agricultural Sciences, Nagoya University, Nagoya 464-01, Japan
}

\begin{abstract}
An adult male house musk shrew with an $X X Y$ sex chromosome constitution was found in a laboratory-bred colony. Maternal origin of the additional $X$ chromosome was demonstrated. The external appearance of the animal was normal, but the testes were small and displayed a high density of interstitial cells. The seminiferous tubules were narrow and contained only Sertoli cells.
\end{abstract}

\section{Introduction}

The $X X Y$ condition has been reported for man (Klinefelter syndrome: Ferguson-Smith et al., 1960; Hamerton et al., 1975; Abyholm and Stray-Pedersen, 1981) and many species of mammal: tamar wallaby (Sharman et al., 1970), common shrew (Searle, 1984), mouse (Cattanach, 1961), black rat (Yosida, 1979), Chinese hamster (Ivett et al., 1978), wood lemming (Gropp et al., 1976), pig (Breeuwsma, 1968; Hancock and Baker, 1981), bull (Scott and Gregory, 1965), sheep (Bruere et al., 1969), goat (Bhatia and Shanker, 1992), horse (Kubien et al., 1993), cat (Centerwall and Benirschke, 1975; Hageltorn and Gustavsson, 1981) and dog (Clough et al., 1970). In all these species, the $X X Y$ condition results in a male phenotype with small testes that lack germ cells (Cattanach, 1974).

The present paper describes an adult house musk shrew (Suncus murinus L.) with an XXY sex chromosome constitution found in a laboratory colony.

\section{Materials and Methods}

The XXY male was detected during cytogenetic screening of the laboratory SK stock of Suncus murinus. This stock had been established by crossing two strains of S. murinus: KAT and SRI. The KAT strain was derived from a wild population of Katmandu, Nepal (Oda et al., 1992) and has been shown to have $2 n=40$ (Rogatcheva et al., 1996). The SRI strain was derived from the animals captured on the West coast of Sri Lanka (Ishikawa et al., 1989) and differs from the KAT strain in five Robertsonian fusions $\mathrm{Rb}(8.17), \mathrm{Rb}(9.13), \mathrm{Rb}(10.12)$, $\mathrm{Rb}(11.16), \mathrm{Rb}(14.15)$ and an insertion of heterochromatin at chromosome 7 . Sex chromosomes of the SRI strain differ substantially from those of the KAT strain and can be identified unambiguously. The SRI $X$ chromosome $\left(X^{S}\right)$ has an additional $\mathrm{C}$-band at the $\mathrm{p}$-arm compared with the KAT $X$ chromosome $\left(X^{K}\right)$. The SRI $Y$ chromosome $\left(Y^{S}\right)$ is much longer than the KAT $Y$ chromosome $\left(Y^{K}\right)$ and differs in both the $\mathrm{G}$ - and $\mathrm{C}$-banding patterns. All these variant chromo-

Received 16 July 1997. somes are present in the hybrid SK stock (Rogatcheva et al., 1997).

Metaphase chromosomes were prepared from a primary culture of fibroblasts and bone marrow cells as described by Rogatcheva et al. (1996). G-band staining was performed according to the method of Seabright (1971), as modified by Grafodatsky and Radjabli (1988). Slides were treated with a $0.025 \%(\mathrm{w} / \mathrm{v})$ trypsin solution in isotonic saline for $\mathrm{I}-2 \mathrm{~min}$ at room temperature, rinsed in $2 \times \mathrm{SSC}$ and stained for $5 \mathrm{~min}$ in $4 \%(w / v)$ Giemsa solution.

The fresh weight of paired testes was scored in the $X X Y$ male and his two half-brothers (control males). The genitalia were fixed in formalin. Standard histological sections $(5 \mu \mathrm{m}$ thick) were prepared from the left testis and stained with haematoxylin and eosin. The diameter of the seminiferous tubules was measured with a micrometer eyepiece on 10 tubules.

\section{Results}

\section{Karyotype}

The karyotype of the XXY male is shown (Fig. 1). All the G-banded spreads of fibroblasts (11) and bone marrow cells (50) scored for karyotype had a chromosome composition of $40 X X Y$ and contained $\mathrm{Rb}(11,16)$ in heterozygous state. The chromosome preparations provided no indication of sex chromosome mosaicism.

The father of the XXY male was a representative of the SK stock and had a karyotype of $35 \mathrm{XY}, \mathrm{Rb}(8.17) /+, \mathrm{Rb}(9.13) /+$, $\mathrm{Rb}(11.16) / \mathrm{Rb}(11.16), \mathrm{Rb}(14.15) /+$. He was crossed with six females of KAT strain and produced five daughters and six sons, all of which were $R b(11.16) /+$. The $X$ and $Y$ chromosomes of the father of the $X X Y$ male were classified as the SRI type $\left(X^{S}, Y^{S}\right)$ according to Rogatcheva et al. (1997). The mother of the $X X Y$ male was representative of the KAT strain and had 40XX. Her $X$ chromosomes were typical $X^{K}$.

Both $X$ chromosomes of the $X X Y$ male were of the KAT type $\left(X^{K}\right)$. The $Y$ chromosome was of the SRI type $\left(Y^{S}\right)$. These observations indicate unambiguously that the $X X Y$ male inherited both $X$ chromosomes from his mother. 


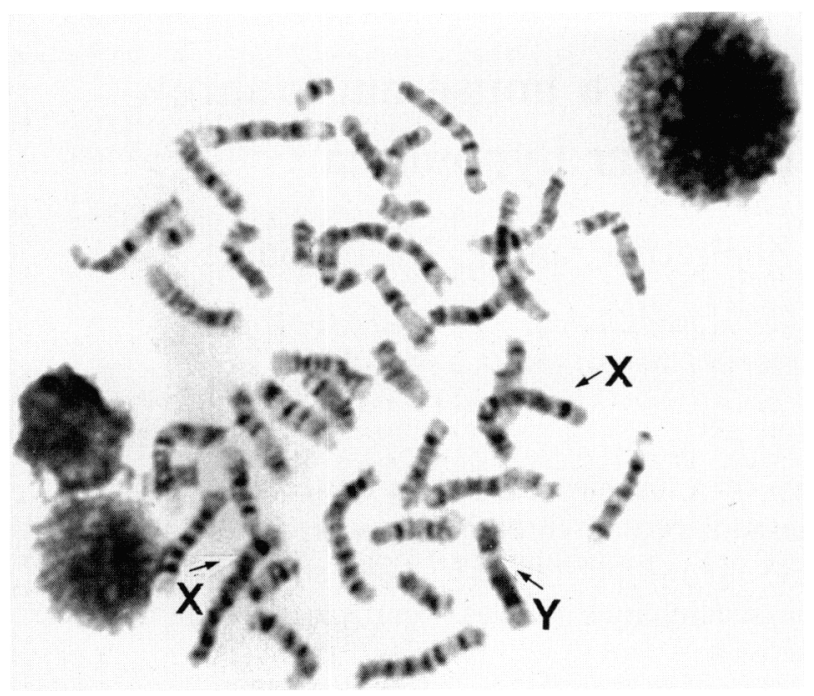

Fig. 1. G-banded chromosome spread of the XXY Suncus murinus. The arrows indicate the sex chromosomes.

\section{Studies of the reproductive system}

The XXY male had a normal male phenotype, as indicated by its external appearance and the size of its accessory reproductive structures. The epididymis, vas deferens and prostate glands were of a size and appearance similar to those observed in the control males. However, the testes of the XXY male were very small in comparison with those of normal adult males. The left testis of the XXY male weighed $5.0 \mathrm{mg}$, while those of his half-brothers weighed $117 \pm 15 \mathrm{mg}$ (mean $\pm \mathrm{SE}$ ).

The histological examination revealed considerable differences in the structure of testes of the XXY male and the control males (Fig. 2). The seminiferous tubules of the XXY male were smaller (average diameter \pm SE was $50 \pm 6 \mu \mathrm{m}$ ) and less complex than those of the control males $(200 \pm 19 \mu \mathrm{m})$, which displayed normal spermatogenic activity. Only one type of cell, located near the basal membrane, was found within the tubules of the XXY male. These cells resembled the Sertoli cells of control males on the basis of size, shape and staining of nuclei.

There was also a remarkable difference in the interstitial tissue from the $X X Y$ and control males. In the XXY male, most of the testis volume consisted of interstitial tissue (Fig. 2a), whereas in the control males, there were only small groups of interstitial cells between the seminiferous tubules (Fig. 2b).

\section{Discussion}

The phenotypic manifestation of the $X X Y$ condition in S. murinus agrees well with that found in other mammals. As in other species, there is a male phenotype in terms of external appearance and accessory reproductive structures, while the presence of small testes appears to be a general feature (Cattanach, 1974).

The histology of the testis of the XXY S. murinus resembles that observed in other adult mammals with the $X X Y$ condition. In all $X X Y$ animals in which the testes have been examined histologically, narrow and simplified tubules lined with Sertoli (a)

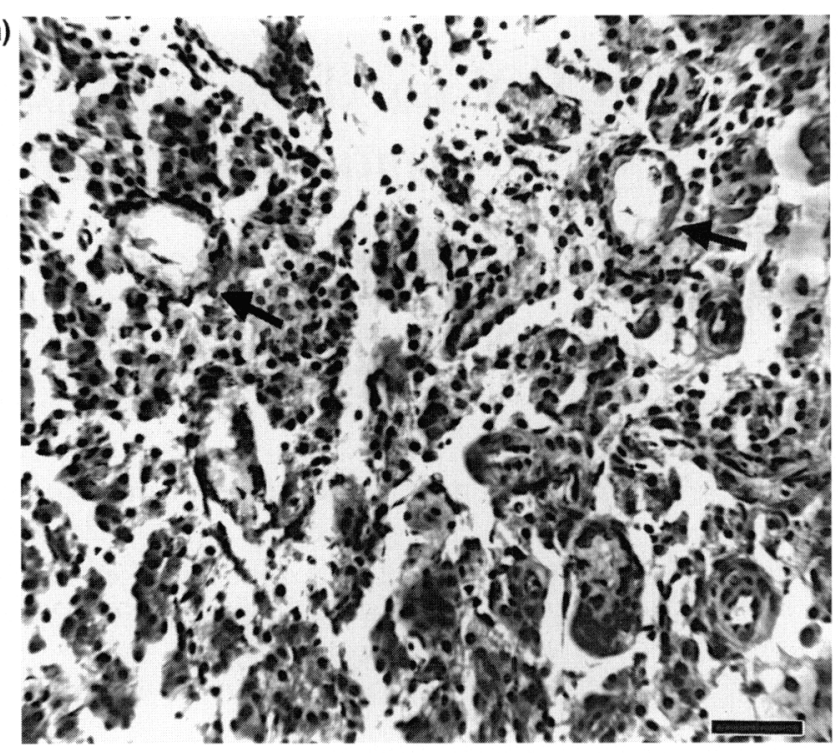

(b)

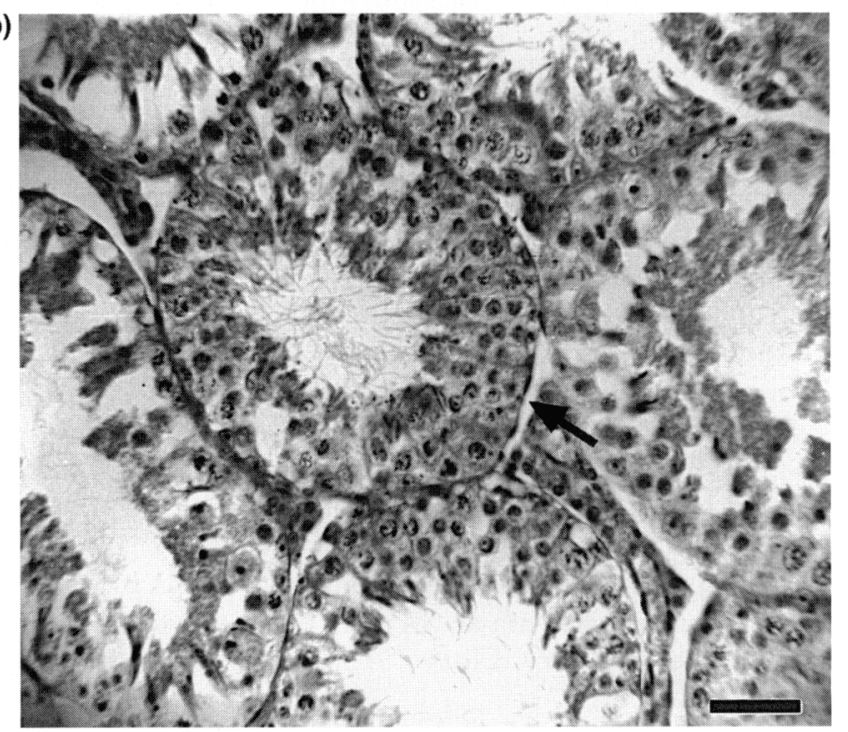

Fig. 2. Histological section of the left testis of (a) the XXY Suncus murinus showing the narrow seminiferous tubules and high density of the interstitial cells and of (b) a control shrew showing normal spermatogenesis. Arrows indicate seminiferous tubules. Scale bars represent $50 \mu \mathrm{m}$.

cells have been reported. Interstitial cell hyperplasia has also been noted as a characteristic of the $X X Y$ condition in many species. In the $X X Y$ male shrew, most of the testis volume consists of interstitial tissue.

Klinefelter syndrome is probably the most common sex chromosomal aberration found in humans. In random surveys, it has been found in about $I$ in every $500-1000$ liveborn males (Epstein, 1986; Chandley, 1988). In the work presented here, one XXY male was found among 143 karyotyped males of S. murinus.

Parental origin of the additional sex chromosome in humans has been examined in several studies (Jacobs et al., 1988; Lorda-Sanchez et al., 1992; MacDonald et al., 1994). The proportion of paternally and maternally derived cases was close to 1:1. With regard to the cell division of origin, 
MacDonald et al. (1994) found that among 107 maternally derived aneuploids 73 were the result of an MI error, 24 the result of a MII error and 10 the result of a post-zygotic mitotic error involving the maternal $X$ chromosome. In the present case, the additional $X$ chromosome of the $X X Y$ shrew was shown to be of maternal origin. However, it was not possible to determine whether the error occurred during maternal MI or MII because the mother of $X X Y$ shrew was an $X^{K} X^{K}$ homozygote. Female $S$. murinus have a rather high rate of premature desynapsis of $X$ chromosomes at diplotene (Borodin et al., 1994) and this may cause a non-disjunction at MI. We consider that post-zygotic mitotic error, as the cause of aneupoidy, is unlikely because both tissues studied contained $X X Y$ cells only.

It is believed that multiple heterozygosity for chromosome rearrangements increases the risk of non-disjunction of heteromorphic and homomorphic chromosomes (de Boer and de Jong, 1989; Speed, 1989). As the stock examined in the present work was of hybrid origin, the majority of SK shrews were multiple heterozygotes for different autosome and gonosome rearrangements (Rogatcheva et al., 1997). Paradoxically, the $X X Y$ shrew received the additional $X$ chromosome from his mother of the KAT strain, which was homozygous for all standard chromosomes, and not from his father, which was heterozygous for as many as three Robertsonian translocations.

This work was supported by research grants from the Ministry of Education, Science, Sports and Culture of Japan and Russian Fund for Basic Research (9615-97738). M. B. Rogatcheva was in receipt of a scholarship from Aichi Prefecture Government.

\section{References}

Abyholm T and Stray-Pedersen S (1981) Hypospermiogenesis and chromosome aberrations. A clinical study of azoospermic and oligozoospermic men with normal and abnormal karyotype International Journal of Andrology 4 546-558

Bhatia S and Shanker V (1992) First report of a XX/XXY fertile goat buck Veterinary Record 130 271-272

Borodin P, Oda S, Takagishi Y, Inouye M and Yamamura H (1994) Meiotic prophase in the fetal ovary of the house musk shrew, Suncus murinus. Cytologia 59 465-469

Breeuwsma AJ (1968) A case of XXY sex chromosome constitution in an intersex pig Journal of Reproduction and Fertility 16 119-120

Bruere AN, Marshall RB and Ward DPJ (1969) Testicular hypoplasia and XXY sex chromosome complement in two rams: the ovine counterpart of Klinefelter's syndrome in man Journal of Reproduction and Fertility 19 103-108

Cattanach BM (1961) XXY mice Genetical Research 2 156-158

Cattanach BM (1974) Genetic disorders of sex determination in mice and other mammals. In 4th International Conference on Birth Defects pp 129-141 Eds AG Motulsky and W Lentz. Excerpta Medica, Amsterdam

Centerwall WR and Benirschke K (1975) An animal model for the XXY Klinefelter's syndrome in man: tortoiseshell and calico male cats American Journal of Veferinary Research 36 1275-1280

Chandley AC (1988) Meiotic studies and infertility. In Cytogenetics of Autosomal Rearrangements pp 361-382 Ed. A Daniel. Alan R Liss, New York
Clough E, Pyle RL, Hare WCD, Kelly DF and Patterson DF (1970) An XXY sex-chromosome constitution in a dog with testicular hypoplasia and congenital heart disease Cytogenetics 9 71-77

de Boer $\mathbf{P}$ and de Jong JH (1989) Chromosome pairing and fertility in mice. In Fertility and Chromosome Pairing: Recent Studies in Plants and Animals pp 37-76 Ed. GB Gillies. CRC Press, Boca Raton, FL

Epstein CI (1986) The Consequences of Chromosome Imbalance Cambridge University Press, Cambridge

Ferguson-Smith MA, Lennox B, Stewart JSS and Mack WS (1960) Klinefelter's syndrome Memoirs of Society of Endocrinology 7 173-18I

Grafodatsky AS and Radjabli SI (1988) Chromosomes of Farm and Laboratory Animals. Nauka, Novosibirsk (in Russian)

Gropp A, Winking H, Frank F, Noack G and Fredga K (1976) Sex-chromosome aberrations in wood lemmings (Myopus schisticolo) Cytogenetics and Cell Genetics 17 343-358

Hageltorn $M$ and Gustavsson I (1981) XXY-trisomy identified by banding techniques in a male tortoiseshell cat Journal of Heredity 72 132-134

Hamerton JL, Canning N, Ray M and Smith S (1975) A cytogenetic survey of 14,069 newborn infants I. Incidence of chromosome abnormalities Canadian Journal of Genetics 8 223-243

Hancock JL and Baker MG (1981) Testicular hypoplasia in a boar with abnormal sex chromosome constitution ( 39 XXY) Journal of Reproduction and Fertility 61 395-397

Ishikawa A, Akadama I, Namikawa T and Oda S (1989) Development of a laboratory line (SRI line) derived from the wild house musk shrew, Suncus murinus, indigenous to Sri Lanka Experimental Animals 38 231-237

Ivett JL, Tice RR and Bender MA (1978) Y two X's? An XXY genotype in Chinese hamster, C. griseus. Journal of Heredity 69 128-129

Jacobs PA, Hassold TJ, Whittington E, Butler G, Collyer S, Keston M and Lee M (1988) Klinefelter's syndrome: an analysis of the origin of the additional sex chromosome using molecular probes Annals of Human Genetics 52 93-109

Kubien EM, Pozor MA and Tischner M (1993) Clinical, cytogenetic and endocrine evaluation of a horse with a $65, \mathrm{XXY}$ karyotype Equine Veterinary Journal $25 \quad 333-335$

Lorda-Sanchez I, Binkert F, Maechler M, Robinson WP and Schinzel AA (1992) Reduced recombination and paternal age effect in Klinefelter syndrome Human Genetics 89 524-530

MacDonald M, Hassold T, Harvey J, Wang LH, Morton NE and Jacobs P (1994) The origin of $47, X X Y$ and $47, X X X$ aneuploidy: heterogeneous mechanisms and role of aberrant recombination Human Molecular Genetics 3 1365-1371

Oda S, Koyasu K and Shrestha KC (1992) Breeding of the house musk shrew, Suncus murinus, originating from a wild population in Katmandu. Nepal Annals Research Institute of Environmental Medicine 43 239-240

Rogatcheva MB, Borodin PM, Matsuda Y and Oda S (1996) Standard karyotype of the house musk shrew, Suncus murinus (Insectivora, Soricidae) Cytologia 61 197-208

Rogatcheva MB, Borodin PM, Oda S-I and Searle JB (1997) Robertsonian chromosomal variation in the house musk shrew Suncus murinus (Insectivora, Soricidae) and the colonisation history of the species Genome $4018-24$

Scott CD and Gregory PW (1965) An XXY trisomic in an intersex of Bos taurus. Genetics 52 473-474

Seabright M (1971) A rapid branding technique for human chromosomes Lancet $7731971-972$

Searle JB (1984) A wild common shrew (Sorex araneus) with an XXY sex chromosome constitution Journal of Reproduction and Fertility 70 353-356

Sharman GB, Robinson ES, Walton SM and Berger PJ (1970) Sex chromosomes and reproductive anatomy of some intersexual marsupials journal of Reproduction and Fertility $2157-68$

Speed RM (1989) Heterologous pairing and fertility in humans. In Fertility and Chromosome Pairing: Recent Studies in Plants and Animals pp 1-35 Ed. GB Gillies. CRC Press, Boca Raton, FL

Yosida TH (1979) Sex chromosome anomalies in $F_{2}$ hybrids between Oceanian and Ceylonese type black rats Japanese Journal of Genetics 54 27-34 